\title{
Biliary Cannulation in Endoscopic Retrograde Cholangiography: How to Tackle the Difficult Papilla
}

\author{
Mark op den Winkel Jörg Schirra Christian Schulz Enrico N. De Toni \\ Christian J. Steib David Anz Julia Mayerle \\ Department of Medicine II, University Hospital, LMU Munich, Munich, Germany
}

\section{Keywords}

Needle-knife precut papillotomy · Double-guidewire technique - Transpancreatic sphincterotomy .

Postendoscopic retrograde cholangiopancreatography pancreatitis · Endoscopic ultrasound-guided biliary drainage

\begin{abstract}
Background: In the setting of a naïve papilla, biliary cannulation is a key step in successfully performing endoscopic retrograde cholangiography. Difficult biliary cannulation (DBC) is associated with an increased risk of post-ERCP pancreatitis and failure of the whole procedure. Summary: Recommendations for biliary cannulation can be divided into (a) measures to reduce the likelihood of a difficult papilla situation a priori and (b) rescue techniques in case the endoscopist is actually facing DBC. (a) Careful inspection of the papillary anatomy and optimizing its accessibility by scope positioning is fundamental. A sphincterotome in combination with a soft-tip hydrophilic guidewire rather than a standard catheter with a standard guidewire should be used in most situations. (b) The most important rescue techniques are needleknife precut, double-guidewire technique, and transpancre-
\end{abstract}

karger@karger.com www.karger.com/ddi

(C) 2021 S. Karger AG, Basel

Karger $\stackrel{2}{5}$ atic sphincterotomy. In few cases, anterograde cannulation techniques are needed. To this regard, the EUS-guided biliary drainage followed by rendezvous is increasingly used as an alternative to percutaneous transhepatic biliary drainage. Key Messages: Biliary cannulation can be accomplished with alternative retrograde or less frequently by salvage anterograde techniques, once conventional direct cannulation attempts have failed. Considering recent favorable data for the early use of transpancreatic sphincterotomy, an adopted version of the 2016 European Society for Gastrointestinal Endoscopy (ESGE) algorithm on biliary cannulation is proposed.

(c) 2021 S. Karger AG, Basel

\section{Introduction}

Since the introduction of alternative imaging modalities of the biliary tract like magnetic resonance cholangiopancreatography or endoscopic ultrasound (EUS), indications for endoscopic retrograde cholangiography (ERC) are for the most part restricted to therapeutic procedures, and purely diagnostic indications (like the sphincter of Oddi dysfunction) are very rare [1]. Biliary 
Fig. 1. Example of papilla protrusion patterns from our department: short, regular, and large oral protrusion patterns and association with difficult cannulation according to Watanabe et al. [9].

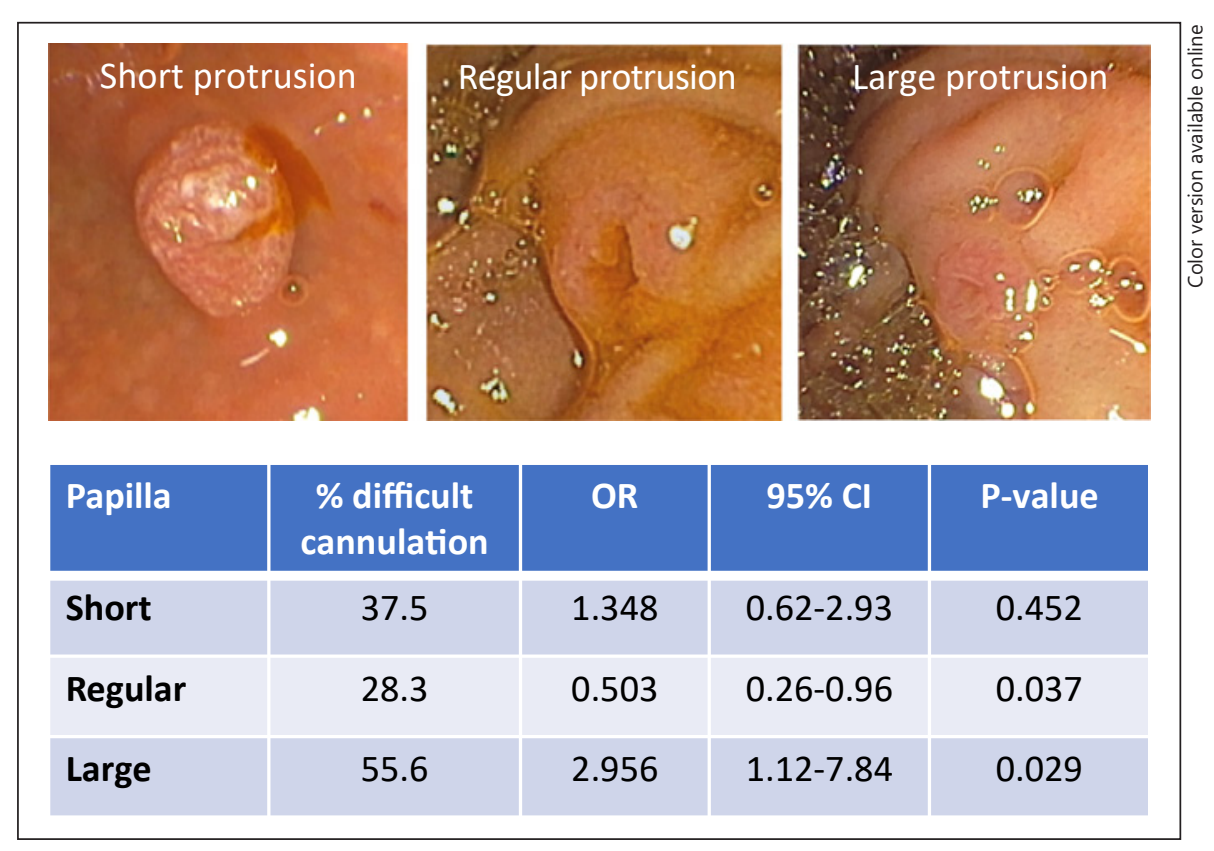

cannulation in the setting of a naïve papilla of Vater is a key step in performing ERC [2]. In analogy to the anesthesiology concept of the "difficult airway management," an interventional GI endoscopist always has to be prepared to be faced with a difficult biliary cannulation (DBC) and should be armed with the gear and concepts necessary for dealing with this demanding endoscopic condition. This includes the knowledge of rescue techniques as well as the handling of material and devices involved. Failure to cannulate the biliary tract is not associated with such acute and dramatic effects as in failed airway management; still additional interventions and possibly subsequent harm due to complications and delayed therapy may be the consequence [3].

\section{Difficult Biliary Cannulation - Definition}

Excluding cases of surgically altered anatomy such as Roux-en-Y anastomosis or Billroth II, DBC rate in ERC is still about 11-20\%, even when performed by expert endoscopists $[4,5]$. There is no universally accepted definition of DBC [6]; however, it is commonly seen as a situation carrying a significant risk for complications as well as failure of the whole ERC procedure $[4,5]$. In a prospective study including 905 Scandinavian patients, the investigators used the risk for postendoscopic retrograde cholangiopancreatography pancreatitis (PEP) as an indicator of difficult cannulation of the naïve papilla [7]. DBC was defined if at least one of the 3 criteria was present as this resulted in a significantly increased rate of PEP: cannulation attempts lasting $>5 \mathrm{~min}, 5$ or more papilla contacts, or 2 guidewire passages into the pancreatic duct (PD) [7]. This definition (plus $>1$ PD opacification) was adopted by the European Society of Gastrointestinal Endoscopy (ESGE) [1]. A current study confirmed the usefulness of these "5-5-2" ESGE criteria in identifying patients at increased risk of PEP and failure of cannulation [8]. The study prospectively recruited 821 patients with a naïve papilla, and if at least one ESGE criterion was present, primary cannulation success rate dropped to $20.4 \%$, while primary cannulation rate was $79.6 \%$ without any of these criteria $(p<0.001)$. The authors concluded that switching to advanced cannulation methods early instead of persistent attempts would be advisable [8]. A retrospective study identified a "large oral protrusion pattern" of the papilla (Fig. 1) as an independent risk factor for DBC [9]. Compared to a regular and short protrusion papilla, it carried the highest risk for PEP and cannulation failure (56\%). The endosonographic finding of a "simultaneous depiction" of the biliary and pancreatic duct at the second portion of the duodenum was found to be a predictor of DBC [10], but the clinical implication of this finding is not clear, especially since EUS is not routinely performed before ERC. The frequency of DBC is associated with the proficiency of the endoscopist. While expert endoscopists op den Winkel/Schirra/Schulz/De Toni/ Steib/Anz/Mayerle 
succeed in $>80 \%$ of biliary cannulation, less trained endoscopists typically fail in $>50 \%$ [11]. Of note, DBC not only increases the risk for PEP but also for bleeding and retroperitoneal perforation as well as the need for prolonged conscious sedation [3].

\section{Prevention of Post-ERCP Pancreatitis}

The incidence of PEP ranges from 3.5 to $9.7 \%$, and $0.1-0.7 \%$ of patients die from PEP [12-14]. A prospective multicenter study with $>1,000$ patients identified endoscopists with $<200$ endoscopic retrograde cholangiopancreatographies (ERCP) to represent an independent risk factor for PEP development [15]. Performance measures for ERCP issued from the ESGE suggest a PEP rate of $<10 \%$ as a surrogate quality indicator [16]. Irrespective of the endoscopist's experience, prophylactic measures can be taken based on an individual assessment to reduce the likelihood of PEP development. The 2020 ESGE guideline on ERCP-related adverse events [14] recommends to administer $100 \mathrm{mg}$ of rectal indomethacin or diclofenac preinterventionally in every patient without contraindications to nonsteroidal anti-inflammatory drugs (NSAID) since most meta-analyses found a significant reduction of PEP risk for this approach $[17,18]$. Furthermore, in those patients with unintended PD guidewire insertion, PD opacification, or double-guidewire cannulation, a short 5F PD stent should be placed ("difficult cannulation with easy pancreatic stenting") [14]. Aggressive hydration with lactated Ringer's solution $(3 \mathrm{~mL} / \mathrm{kg} / \mathrm{h})$ should be started before ERCP whenever contraindications for NSAID are present and contraindication for high-volume hydration are absent. Continuing hydration postinterventionally with $20 \mathrm{~mL} / \mathrm{kg}$ bolus followed by $3 \mathrm{~mL} / \mathrm{kg} / \mathrm{h}$ for $8 \mathrm{~h}$ is recommend in patients without PD stent placement, while PD stent placement should result in a stop of high-volume therapy postinterventionally [14]. Due to the lack of solid data, the ESGE does not suggest the routine combination of NSAID with other PEP prevention methods [14].

\section{How to Reduce the Frequency of DBC Situations}

\section{Anatomical Considerations}

Mastering a complex endoscopic procedure like biliary cannulation requires a detailed comprehension of the anatomy involved $[2,19]$. The papilla of Vater is normally located in the descending part of the duodenum (Fig. 2).

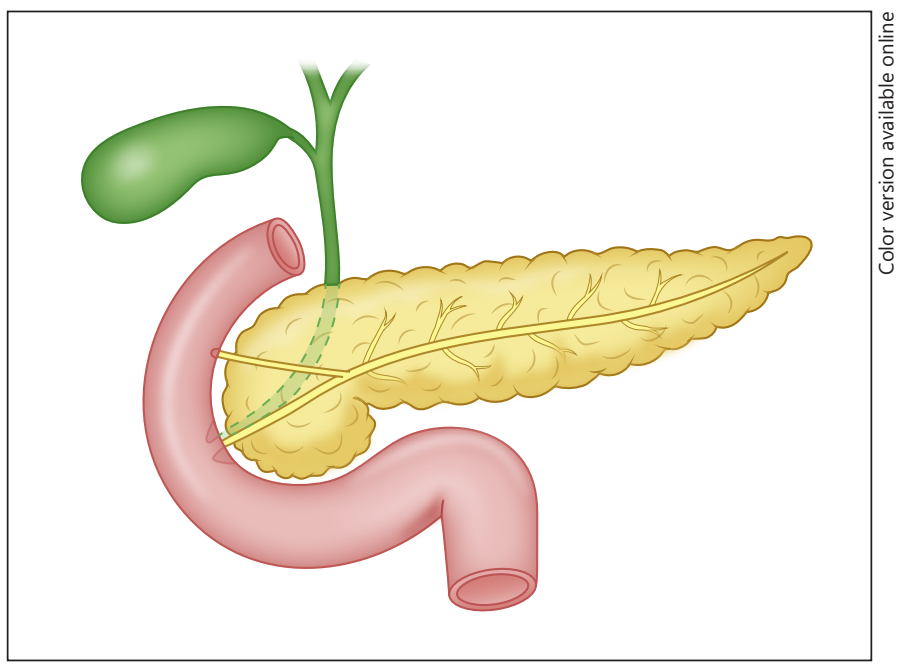

Fig. 2. Duodenal and biliary/pancreatic anatomy.

Put simply, the papilla is an elevation with a sphincter muscle on the underlying ampulla Vateri, which contains the PD and common bile duct (CBD) orifice. The hepatopancreatic sphincter of Oddi controls the excretory outflow of bile and pancreatic juice. A number of anatomical variants exist regarding size of the papilla (long, short, and flat), shape, and orientation (e.g., facing downwards) as well as of the union of the 2 excretory ducts (long common channel, short common channel, PD, and CBD opening into separate orifices without a common channel) $[19,20]$ (Fig. 3a). Intubation of the CBD is a more complex task than cannulation of the PD. The CBD initially runs fairly parallel to the duodenal wall, so it has to be intubated in a rather tangential fashion, while the PD runs perpendicular to the duodenal wall, facilitating straight cannulation (Fig. 3b). For biliary cannulation, the papilla is best approached from below, aiming at aligning the axis of the catheter/sphincterotome and the CBD, which usually runs in the 11(-12) o'clock direction. Another challenge to the endoscopist is the typically Sshaped segment of the intraduodenal portion of the CBD (Fig. 3b).

\section{Factors Favoring Cannulation Success}

The single most relevant factor for cannulation success undoubtedly is the level of experience of the operator [21, $22]$. The cannulation rate of a naïve papilla is widely regarded as the most appropriate surrogate of competence in ERC training [21-23]. A single-center, single-operator learning curve assessment disclosed a successful cannulation rate of $43 \%$ at the beginning of supervised ERCP 
Fig. 3. a Anatomical variants of $P D$ and CBD fusion. Frequency of variants. Adopted from Millbourn [20]. b S-shaped CBD and straight $\mathrm{PD}$. PD, pancreatic duct; $\mathrm{CBD}$, common bile duct.

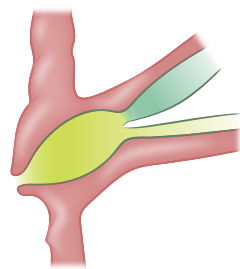

$85 \%$ : long common channel, classical ampulla

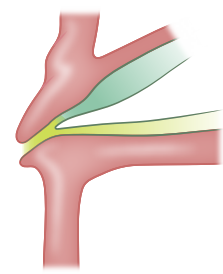

6\%: short common channel, no classical ampulla

b

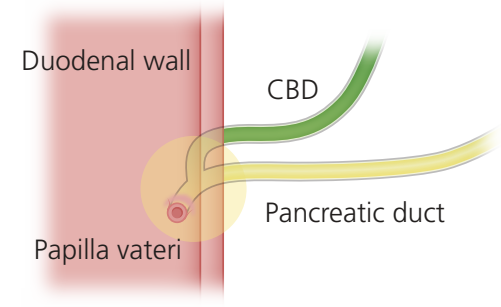

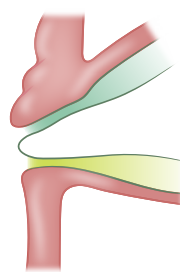

9\%: no fusion, duct open seperately

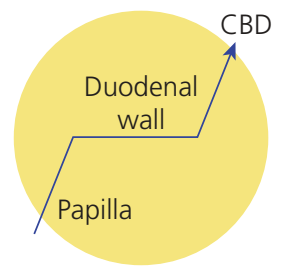

training, while this rose to $>80 \%$ after 400 supervised procedures and reached $>96 \%$ as an unsupervised expert [11]. A successful bile duct cannulation rate of at least $90 \%$ in patients with normal anatomy is considered a key performance measure by the ESGE [16]. It is of utmost importance that during the long learning process towards this goal, close supervision by an expert endoscopist is guaranteed. The supervisor should not only actively teach and demonstrate standard and advanced cannulation skills but also how to avoid and manage ERC-related complications. The supervisor has to identify the right moment when to take over the endoscope from the trainee to avoid harm to the patient [1]. In a multicenter, prospective, observational study at 6 European high- and low-volume ERC centers, involvement of trainees within a proper teaching setting did not negatively affect safety and success rates of the ERCP procedure [24]. Regardless of the endoscopist's experience, general recommendations can be made to increase the likelihood of successful cannulation. First, thorough inspection of the papilla and optimizing its visualization and accessibility by scope positioning is key $[1,9]$. In most cases, this goal is achieved by shortening the endoscope in the second part of the duodenum (short radiographic scope position) and placing the duodenoscope just inferior to the papilla. However, this position is not obligatory since in some settings (for instance, with anatomical variants of more proximal or distal papilla location), optimal accessibility of the papilla requires different scope positions or even repositioning of the patient in the left lateral or supine position [25]. Biliary cannulation is a 2 -step process. First, the tip of the catheter/papillotome is carefully inserted into the orifice ("insinuation") followed by deep cannulation [25]. Here, manipulation of the scope (small wheel to the left and pulling back the scope followed by small wheel back to the right) helps in overcoming the typically S-shaped segment of the intraduodenal portion of the CBD (Fig. 3b). Any unnecessary trauma and pressure to the papilla must be avoided during this critical maneuver, since it increases the PEP risk. The sphincterotome should be preferred over the standard catheter because of its higher cannulation success rate [26]. Cannulation of the papilla is also a prerequisite for endoscopic sphincterotomy, which is necessary for most biliary interventions [1], and a sphinc- 
terotome is needed at this point, anyhow. However, certain situations like first steps in ERCP training, very small papilla, or cannulation after a precut may favor other cannulation instruments such as the ball tip or filiform tip catheters which are deemed less traumatic. Wire-guided cannulation is beneficial regarding PEP risk (RR 0.51), cannulation success (RR 1.07), and need for precutting (RR 0.75) compared to nonwire-guided cannulation techniques including opacification [27]. The diameter of the guidewire ( 0.035 vs. $0.025 \mathrm{inch}$ ) is not a relevant factor for cannulation success [28]. The tip should be hydrophilic to facilitate the passage of the typically S-shaped segment of the CBD. Especially in this area, the ability of the sphincterotome to adjust through manipulation of the cutting wire is helpful since it allows changing the angle of approach to the papilla as well as to "hook" a downward-facing papilla [29]. In a prospective randomized controlled study [30], the highly flexible ("softtipped") guidewire reduced cannulation time and papilla attempts compared to a standard ("stiff-shaft") guidewire, yet there was only a nonsignificant trend towards a higher cannulation rate ( 96 vs. $86 \% ; p=0.08$ ). Bassi et al. [31] conducted a prospective multicenter randomized trial: the "touch-technique" (engaging the papilla with the sphincterotome first for $1-3 \mathrm{~mm}$ and then advancing the guidewire) was superior regarding the cannulation success rate when compared to the "nontouch technique" (guidewire as the primary cannulation device is protruded 1-3 $\mathrm{mm}$ beyond the sphincterotome tip and advanced gently in the CBD) [31]. Injecting a small amount of contrast helps in understanding the anatomy, but the advantage of this information must be weighed against the risk of PEP.

In most cases, the contact point should be the left upper quadrant of the papilla and then aiming towards the 11-12 o'clock position. In this maneuver, the tip of the sphincterotome and the wire should be perpendicular to the orifice of the papilla, and the initial path should be "uphill" [25]. When the endoscopist anticipates a DBC based on inspection or when it develops early in the course, this should not be dealt with by an ERCP trainee but by the supervising operator [14].

\section{Alternative Biliary Cannulation Strategies}

In a stable patient, repeat ERC after papilla swelling has resolved (24-48 h) can be a strategy in failed standard cannulation to finally achieve transpapillary access $[1$, 14]. On the other hand, this requires an additional proce-

Management of Difficult Biliary

Cannulation dure, prolonged hospital stay, and still provides no guarantee for successful standard cannulation. Thus, most experienced endoscopists will switch to rescue techniques to obtain biliary access in the course of the same ERC procedure. With these advanced techniques, total biliary cannulation success rate can be as high as $99 \%[8,32]$ with acceptable rates of complications [33]. All retrograde rescue techniques presented here should ideally be carried out independently only by expert endoscopists as defined by the ESGE: achieving selective biliary cannulation in $>80 \%$ of cases when using standard cannulation $[1,34]$. This recommendation emphasizes the fact that the number of cases requiring alternative cannulation techniques declines with increasing ERCP capability [6]. However, the obligation to be proficient in these techniques remains high, particularly for teaching hospital expert endoscopists supervising ERC trainees.

\section{Needle-Knife Precut Techniques (NKPP and NKF)}

$\mathrm{DBC}$ without involuntary cannulating the PD is usually managed by precutting with a needle-knife, which has a success rate of 70-90\% [6]. Two different needleknife precutting techniques exist: first, in the conventional needle-knife precut papillotomy (NKPP), the papillary incision starts at the 11 o'clock margin of the orifice aiming upwards at the CBD. Second, the needle-knife fistulotomy $(N K F)$ : here, the initial incision is at the roof of the papilla and then aiming up- or downwards subject to the specific anatomy. NKF usually spares the delicate orifice area, reducing the risk of current-related PD damage and subsequent PEP. Based on a meta-analysis [35], the ESGE recommends NKF as the preferred precutting method due to its significantly lower PEP rate $[1,35]$. The generally low PEP risk of NKF is supported by 2 studies published in 2019 and 2020 [36, 37]. However, NKF is especially favorable in certain anatomical constellations (e.g., large ampullas and impacted stones) [38], and it is still infrequently performed compared to NKPP in the clinical routine. When access to the PD is easy to obtain, PD stenting prior to precutting can be recommended $[1,39]$. Irrespective of the precutting method, experienced endoscopists should switch to precutting rather early, since the increased risk of PEP is thought to occur at least in part in consequence of the local trauma caused by repeated conventional cannulation attempts. Several metaanalyses investigated the actual effect on PEP risk, and most of them described a significant PEP reduction for the early precut group (2.5\% [early precut] vs. $5.3 \%$ [persistent cannulation attempts]) [40], while others could demonstrate a nonsignificant trend in the same direction. 


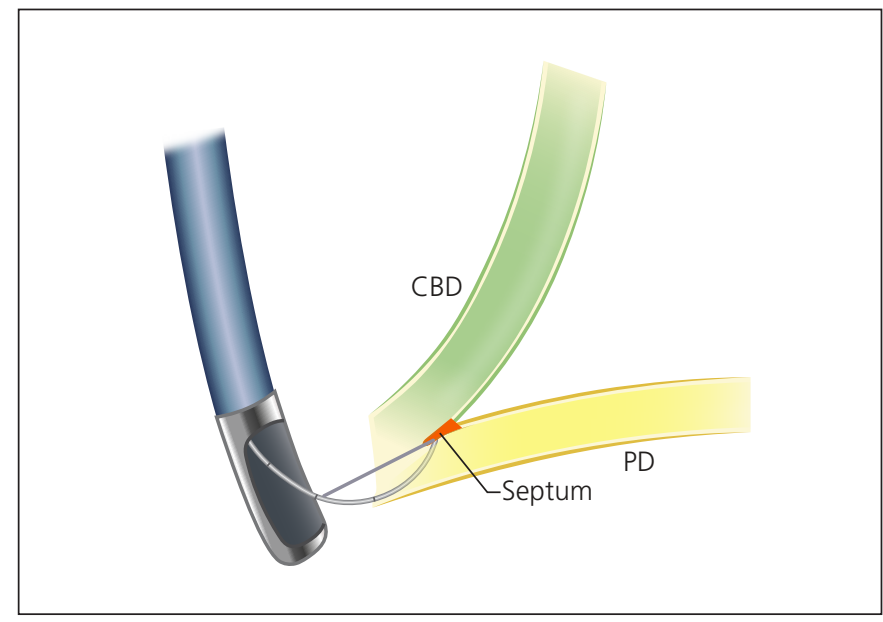

Fig. 4. TPS: in the setting of failed CBD cannulation and guidewire placement in the $\mathrm{PD}$, the sphincterotome is positioned in the distal part of the PD. In the next step, sphincterotomy is performed by slightly rotating the endoscope cutting in the direction of the 11 o'clock area of the papilla to expose the CBD. Following this maneuver, cannulation of the CBD is successful in most cases. Adopted from Barakat et al. [57]. TPS, transpancreatic sphincterotomy; $\mathrm{PD}$, pancreatic duct; $\mathrm{CBD}$, common bile duct.

A meta-analysis in 2015 saw a significant PEP reduction in a more homogeneous subgroup in which early precut was exclusively performed by expert endoscopists [41], and this observation was confirmed by Tang et al. [42]. Chen et al. [43] conducted the most recent meta-analysis including 6 studies. Compared with persistent standard cannulation, early precutting decreased the PEP rate.

\section{Double-Guidewire Technique}

Due to the anatomical circumstances (Fig. 3b), it is not uncommon for the guidewire to accidentally pass into the PD. Once this happens repeatedly, one can leave the guidewire in place, and use it as an aid when trying to cannulate the CBD with a second wire (double-guidewire [DGW] technique) $[1,44]$. The sphincterotome is placed above the PD wire and pushes it out of the way, so CBD cannulation with the second guidewire is facilitated. Additionally, the PD wire helps in straightening the typically S-shaped distal CBD segment (Fig. 3b). A multicenter randomized controlled trial showed that converting to a DGW technique did not facilitate CBD cannulation nor did it reduce PEP risk when compared with repeated use of a single-wire technique [45]. A meta-analysis found a significant increase in PEP for DGW compared to other rescue strategies in difficult cannulation [46]. The PEP risk was increased when using this technique exclusively
(RR 1.98). Nevertheless, one of the studies included in the meta-analysis showed a reduced PEP risk when combined with PD stenting [47]. The ESGE recommends insertion of a pancreatic stent to reduce PEP risk in patients where a guidewire is already present in the $\mathrm{PD}$, a situation which applies to DGW-assisted cannulation $[1,14,48]$. A major problem of the meta-analysis on DGW is the fact that mainly retrospective data are included and the preventive measures for development of PEP are highly variable [46]. Presumably, DGW will remain a frequently used rescue technique and has the advantage of a short learning curve [49].

\section{Transpancreatic Sphincterotomy}

Especially when encountering a small and flat papilla or with unstable scope position, traditional freehand precutting may be difficult. At this point, transpancreatic sphincterotomy (TPS) can be beneficial and showed significantly higher cannulation success $(94.1 \%)$ when compared to DGW (58.8\%) [50]. TPS represents a variation of precutting [51] where a guidewire that has accidentally been passed into the PD during DBC is left in place, and the sphincterotome is inserted into the PD $[4,5]$. In the next step, sphincterotomy is performed by slightly rotating the endoscope (ideally without bowing the sphincterotome) directed at the 11 o'clock area to expose the CBD by opening the septum between PD and CBD (Fig. 4). Following this maneuver, cannulation of the CBD is successful in most cases [52]. Likely due to the thermic affection of the PD, TPS is associated with an increased risk of PEP, but insertion of a PD stent in one study resulted in a decreased PEP risk (9 vs. 4\%) [53]. Theoretical concerns of TPS-related long-term consequences like PD stenosis [54] have not been confirmed in one prospective study [52]; however, studies comprising follow-up beyond 1 year have been stipulated [55]. In 2020, 2 retrospective single-center studies from Finland $(n=143)$ [56] and from the Stanford University $(n=369)$ [57] found TPS to be safe even on a long-term scale [56]. Compared to needle-knife precut, a 2017 meta-analysis [32] showed significantly higher biliary cannulation rates and less bleeding complications for TPS, while PEP risk was not significantly different. TPS was labeled a safe and underutilized technique in the DBC setting [32]. Instead of primarily using the DGW technique when unintended PD guidewire has occurred as recommended by the ESGE [1], Pécsi et al. [55] endorsed directly switching to TPS considering the high PEP risk of DGW and its nonsuperior cannulation success rate [46]. When only prospective studies were considered in another systematic review and op den Winkel/Schirra/Schulz/De Toni/ Steib/Anz/Mayerle 
Fig. 5. A EUS-BD, most frequent access routes. B Transgastric access to the left intrahepatic bile duct (typically segment III). $C$ Transduodenal access to the common bile duct. B EUS-BD: transgastric access to the left intrahepatic bile duct. a Transgastric puncture of a dilated segment III bile duct with a 19-G needle. b Contrast injection demonstrates complete truncation of the CBD due to high-grade stenosis in the middle part of the CBD. c The guidewire is passed anterogradely across the stenosis and papilla into the duodenum. Recovery of the wire via the oral route (d) followed by rendezvous ERC (e) and transpapillary drainage with a partially covered $10-\mathrm{mm}$, 6-cm metal stent (f). C EUS-BD: transduodenal access to the CBD.Transduodenal CBD puncture with a $19-\mathrm{G}$ needle (a) and passage of a wire over a high-grade stenosis of the distal CBD into the duodenum $(\mathbf{b}, \mathbf{c})$. Recovery of the wire via the oral route $(\mathbf{d})$ followed by rendezvous ERC with balloon dilatation (e) and transpapillary drainage with a $10 \mathrm{~F}$ stent (f). EUS-BD, endoscopic ultrasonography-guided biliary drainage; CBD, common bile duct; ERC, endoscopic retrograde cholangiography.

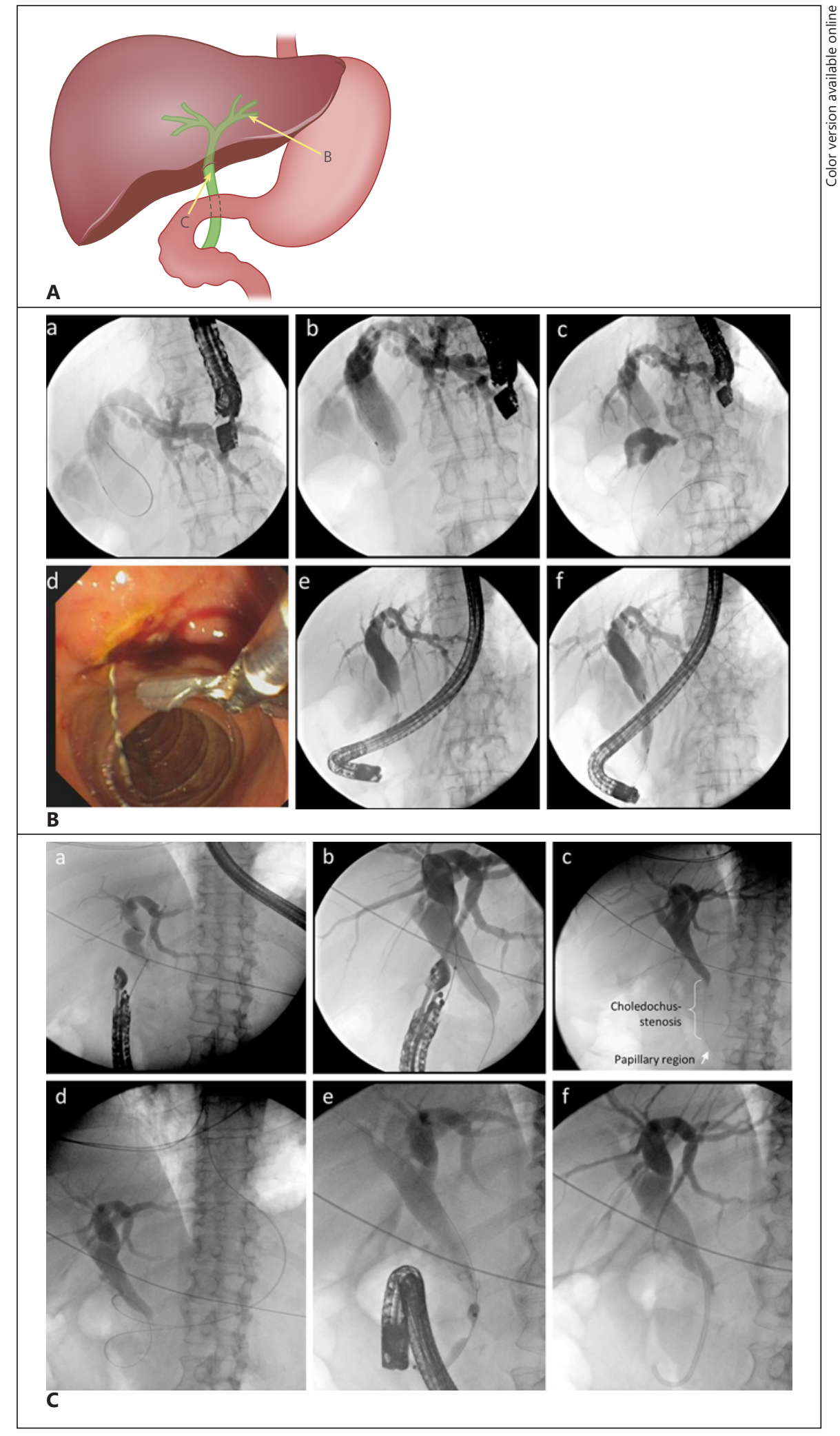




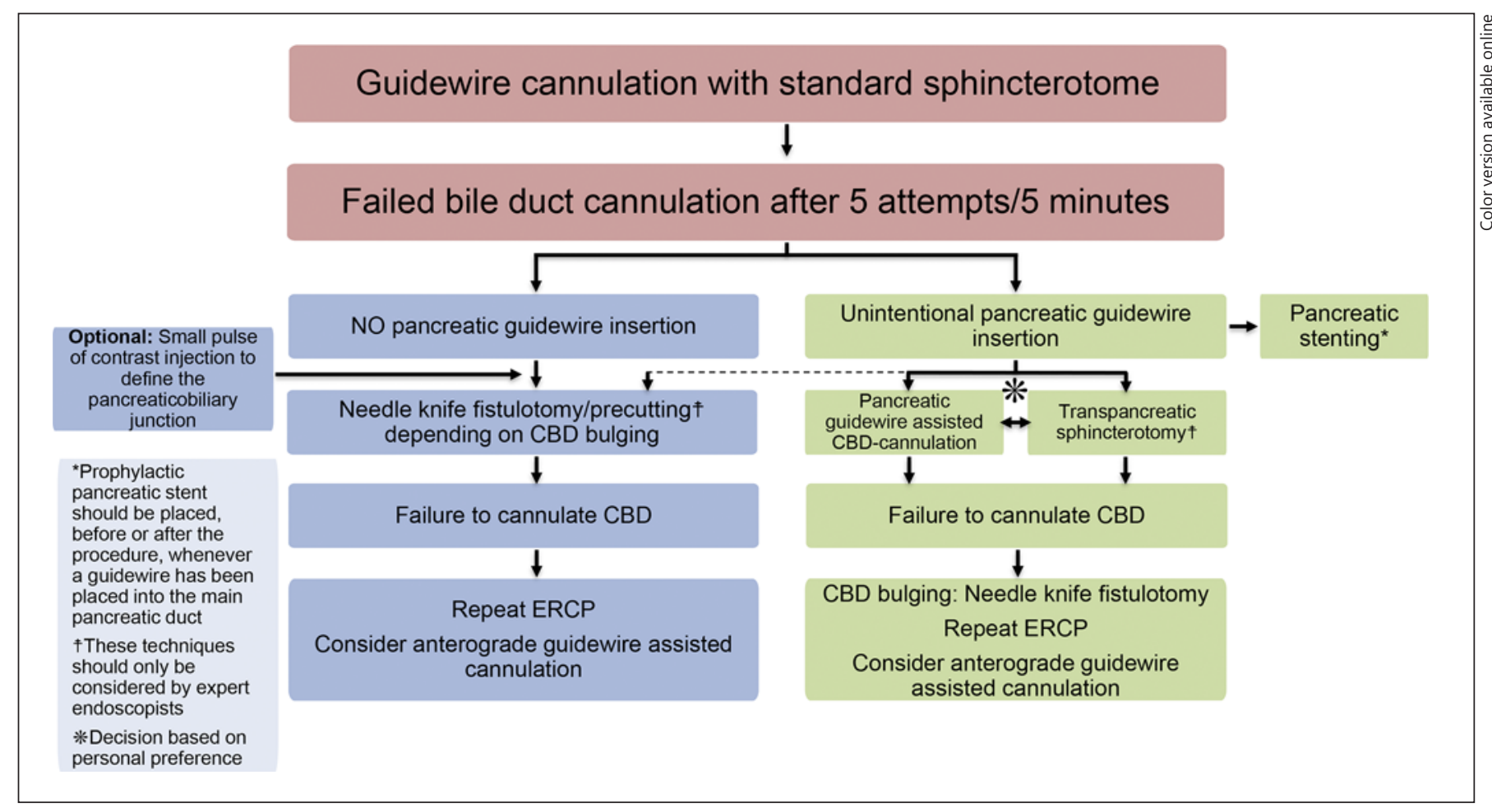

Fig. 6. Evidence-based ESGE algorithm for biliary cannulation in ERCP [1], modified according to local standards and update of evidence $[46,68]$. The exact technique/sequence of techniques for overcoming a DBC situation should always be selected after careful consideration with regard to patient anatomy, underlying pathology, and endoscopist's preference and level of expertise. ERCP, endoscopic retrograde cholangiopancreatography; DBC, difficult biliary cannulation; NKF, needle-knife fistulotomy.

meta-analysis by Pécsi et al. [55], TPS appeared to be superior to DGW and NKPP with regard to cannulation success, while NKF was similarly successful. Risk of PEP was similar in TPS, DGW, and NKPP, however less frequent in NKF, which was also described in a retrospective comparative study by Wen et al. [36]. All 4 techniques had comparable bleeding and perforation rates [55].

\section{Anterograde Access Techniques}

Retrograde cannulation of the CBD fails in $<5 \%$ of cases with normal anatomy [1]. Especially, ampullary pathology like diverticula and malignant infiltration of the papilla as well as distal CBD strictures increase the risk of retrograde cannulation failure. Conventionally, percutaneous transhepatic biliary drainage (PTBD) is offered to patients with failed retrograde access. This is usually followed by rendezvous endoscopy to accomplish internal drainage. However, PTBD is associated with substantial procedure-related and long-term morbidity, and external drainage is not well tolerated by many patients $[58,59]$. In 1996, Wiersema et al. [60] described the feasibility of
EUS-guided cholangiopancreatography, and in 2001, the first therapeutic intervention for biliary drainage using the EUS-guided access was reported [61]. EUS-guided biliary drainage (EUS-BD) as opposed to PTBD has the advantage of an internal drainage applied in a single procedure. In the last 2 decades, a number of variations of EUS-BD have been developed, and it is increasingly used as an alternative for PTBD [62]. According to 2 metaanalyses, EUS-BD showed a success rate of $90 \%$; adverse event rates occurred in approximately $20 \%[63,64]$. Under EUS guidance, using a 19- or 22-G needle, the biliary tract is punctured. Depending on patient anatomy, underlying disease, width of the biliary tracts, and accessibility from the transgastric or transduodenal position (Fig. 5A), the primary puncture site is either intrahepatic (typically segment III; Fig. 5B) or extrahepatic (CBD [Fig. 5C] or rarely the gallbladder) [65]. Subsequently, the correct position is confirmed by bile aspiration and contrast injection, and the guidewire is passed anterogradely across the papilla. After switching to the duodenoscope, the guidewire is used to retrogradely cannulate the $\mathrm{CBD}$, 
which is referred to as EUS-guided rendezvous (Fig. 5B, C). More advanced variants of EUS-BD involve the creation of a fistula and EUS-guided stent placement (e.g., EUS-guided hepatogastric anastomosis and EUS-guided choledochoduodenostomy), but these techniques are usually recommended for malignant obstruction in combination with a nonaccessible papilla [65]. Furthermore, the details of drainage devices used in retrograde cannulation as well as in PTBD and EUS-BD are beyond the scope of this cannulation review. A meta-analysis of 9 studies $(n=483)$ comparing EUS-BD and PTBD after failed ERC examined the primary outcomes, technical success, and adverse events [66]. No difference in technical success was observed, but EUS-BD showed better clinical success (OR 0.45) and less adverse events (OR 0.23). Furthermore, fewer reinterventions were necessary (OR 0.13 ), and EUS-BD was more cost-effective. A retrospective study in the setting of malignant biliary obstruction evaluated ERC versus EUS-BD after failed ERC concerning success of stent placement (94 vs. 93\%) and adverse events (both 8.6\%). PEP risk seemed to be lower with EUS-BD (0 vs. $4.8 \%$ ) [67]. Yet, since EUS-BD is significantly associated with higher complication rate when not performed by exceptionally skilled endoscopists [6], it does not have the potential to replace ERC as the first-line technique on a broad basis.

\section{Modified ESGE Algorithm for Biliary Cannulation}

Considering the multiple factors influencing this decision, the choice of the advanced rescue technique in DBC is always an individualized one. Among others, it is dependent on the center-specific circumstances, operator's preferences, and patient characteristics including papillary anatomy and underlying disease. Although algorithms carry the risk of a too dogmatic approach, they are useful for conceptualizing the available technical options. In 2016, along with its clinical guideline on papillary cannulation and sphincterotomy, the ESGE published an evidence-based algorithm for biliary cannulation [1]. In the setting of unintentional pancreatic guidewire insertion, pancreatic guidewire-assisted cannulation was recommended, and only if this fails, TPS was a possible next option. Considering recent data on the DGW technique, showing significant increase in PEP risk alongside a nonsuperior cannulation success [46], in our institution, TPS would now be on equal footing next to pancreatic guidewire-assisted cannulation in the setting of $\mathrm{DBC}$ and unintended cannulation of the PD (Fig. 6). Furthermore, a prospective randomized multicenter study published in 2021 compared TPS and DGW and found no difference in PEP-risk but a superior biliary cannulation rate for TPS (84.6\% vs. 69.7\%) [68]. Promoting TPS as an advanced technique early in the course of DBC $[50,56,57]$ is also supported by the meta-analysis data displaying a higher cannulation success and lower bleeding rate for TPS even when compared to the long-time standard NKPP [32]. In situations with DBC as defined by the ESGE " $5-5-2$ criteria" [1], a recent study labeled TPS an "effective advanced cannulation method with an acceptable complication rate" [8]. Of course, unintended PD guidewire insertion does not result in an obligation to proceed with wire-guided techniques (TPS or DGW). After placement of a PD stent, switching to a needle-knife precutting technique is an option (Fig. 6), especially with CBD bulging. Despite increasing data on the various retrograde cannulation techniques including meta-analyses, direct comparison of these techniques remains a difficult task. Large multicenter prospective trials comparing these techniques in defined subgroups are not available. Overall, centers and individual endoscopists should use techniques they feel comfortable as well as experienced with and audit their complication rate which is a major quality parameter for ERCP in American and European guidelines [16, 69].

In the case of failed retrograde access, the ESGE algorithm recommends anterograde guidewire insertion percutaneously or via EUS guidance depending on local expertise [1]. Reflecting the results of a 2017 meta-analysis [66], EUS-BD rather than PTBD could be considered a first-line anterograde option provided sufficient EUS and ERCP proficiency and logistics are present. However, these conditions are presently confined to high-volume endoscopy centers, and establishing EUS-BDA as the widely used standard anterograde approach will require widespread application of interventional EUS training. An expert consensus stated that, bearing in mind the risk for serious complications, EUS-BDA should be performed only by endoscopists with large EUS and ERCP experience ( $>4$ years with $>200-300$ EUS and ERCP/ year) with a standard ERCP success rate $>95 \%$. Even if these requirements are fulfilled, surgical and interventional radiology backup is mandatory $[62,70]$.

\section{Conclusion}

Biliary cannulation via the papilla of Vater can be accomplished with alternative strategies, if standard cannulation has failed. The exact strategy for overcoming a 
DBC situation should be selected after careful consideration with regard to patient anatomy, underlying pathology, and endoscopist's level of experience. The ability to be proficient in a variety of techniques is crucial. In the hands of an experienced endoscopist, cannulation of a difficult papilla can finally be achieved in most cases without escalation to anterograde/rendezvous procedures.

\section{Acknowledgement}

The authors thank Dr. Hao Lin for technical assistance in reference management.

\section{Conflict of Interest Statement}

The authors have no conflicts of interest to declare. M.O.D.W and J.M. have received lecture honoraria from Falk. C.S. has received lecture honoraria from Falk and Janssen. J.S. has received lecture honoraria from MSD, Falk, EKW-concept, and GATE Mu- nich. E.N.D.T. has served as a paid consultant for AstraZeneca, Bayer, BMS, EISAI, Eli Lilly \& Co, Pfizer, IPSEN, and Roche. He has received reimbursement of meeting attendance fees and travel expenses from Arqule, AstraZeneca, BMS, Bayer, Celsion, and Roche and lecture honoraria from BMS and Falk. He has received third-party funding for scientific research from Arqule, AstraZeneca, BMS, Bayer, Eli Lilly, and Roche. C.J.S. has received lecture honoraria from Falk, Gilead, AbbVie, Gore, and Norgine.

\section{Funding Sources}

No external funding sources for this study.

\section{Author Contributions}

M.O.D.W. and J.M. conceived and designed the review and drafted the manuscript. J.S., C.S., E.D.T., C.J.S., and D.A. revised it critically for important intellectual content and made substantial contributions to the conception of the work. J.S. additionally contributed in acquisition of endoscopic image material.

\section{References}

1 Testoni PA, Mariani A, Aabakken L, Arvanitakis M, Bories E, Costamagna G, et al. Papillary cannulation and sphincterotomy techniques at ERCP: European Society of Gastrointestinal Endoscopy (ESGE) clinical guideline. Endoscopy. 2016 Jul;48(7):657-83.

2 Baron TH, Kozarek RA, Carr-Locke DL. ERCP. Elsevier Health Sciences; 2018.

3 Williams EJ, Taylor S, Fairclough P, Hamlyn A, Logan RF, Martin D, et al. Are we meeting the standards set for endoscopy? Results of a large-scale prospective survey of endoscopic retrograde cholangio-pancreatograph practice. Gut. 2007 Jun;56(6):821-9.

4 DeBenedet AT, Elmunzer BJ, McCarthy ST, Elta GH, Schoenfeld PS. Intraprocedural quality in endoscopic retrograde cholangiopancreatography: a meta-analysis. Am J Gastroenterol. 2013 Nov; 108(11):1696-705; quiz 705 .

5 Berry R, Han JY, Tabibian JH. Difficult biliary cannulation: historical perspective, practical updates, and guide for the endoscopist. World J Gastrointest Endosc. 2019 Jan 16;11(1):521.

6 Liao WC, Angsuwatcharakon P, Isayama $\mathrm{H}$, Dhir V, Devereaux B, Khor CJ, et al. International consensus recommendations for difficult biliary access. Gastrointest Endosc. 2017 Feb;85(2):295-304

7 Halttunen J, Meisner S, Aabakken L, Arnelo U, Grönroos J, Hauge T, et al. Difficult cannulation as defined by a prospective study of the Scandinavian Association for Digestive Endoscopy (SADE) in 907 ERCPs. Scand J Gastroenterol. 2014 Jun;49(6):752-8.
8 Ismail S, Udd M, Lindström $\mathrm{O}$, Rainio $\mathrm{M}$, Halttunen J, Kylänpää L. Criteria for difficult biliary cannulation: start to count. Eur J Gastroenterol Hepatol. 2019 Oct;31(10):1200-5.

9 Watanabe M, Okuwaki K, Kida M, Imaizumi H, Yamauchi H, Kaneko T, et al. Transpapillary biliary cannulation is difficult in cases with large oral protrusion of the duodenal papilla. Dig Dis Sci. 2019 Aug;64(8):2291-9.

10 Shinoura S, Tokushige A, Chinen K, Mori H, Kato S, Ueda S. Endosonographic finding of the simultaneous depiction of bile and pancreatic ducts can predict difficult biliary cannulation on endoscopic retrograde cholangiopancreatography. PLoS One. 2020;15(7): e0235757.

11 Verma D, Gostout CJ, Petersen BT, Levy MJ, Baron TH, Adler DG. Establishing a true assessment of endoscopic competence in ERCP during training and beyond: a single-operator learning curve for deep biliary cannulation in patients with native papillary anatomy. Gastrointest Endosc. 2007 Mar;65(3):394-400.

12 Andriulli A, Loperfido S, Napolitano G, Niro G, Valvano MR, Spirito F, et al. Incidence rates of post-ERCP complications: a systematic survey of prospective studies. Am J Gastroenterol. 2007 Aug;102(8):1781-8

13 Kochar B, Akshintala VS, Afghani E, Elmunzer BJ, Kim KJ, Lennon AM, et al. Incidence, severity, and mortality of post-ERCP pancreatitis: a systematic review by using randomized, controlled trials. Gastrointest Endosc. 2015 Jan;81(1):143-e9.
14 Dumonceau JM, Kapral C, Aabakken L, Papanikolaou IS, Tringali A, Vanbiervliet G, et al. ERCP-related adverse events: European Society of Gastrointestinal Endoscopy (ESGE) guideline. Endoscopy. 2020 Feb;52(2):12749.

15 Lee HJ, Cho CM, Heo J, Jung MK, Kim TN, $\mathrm{Kim} \mathrm{KH}$, et al. Impact of hospital volume and the experience of endoscopist on adverse events related to endoscopic retrograde cholangiopancreatography: a Prospective Observational Study. Gut Liver. 2020 Mar 15;14(2): 257-64.

16 Domagk D, Oppong KW, Aabakken L, Czakó L, Gyökeres T, Manes G, et al. Performance measures for endoscopic retrograde cholangiopancreatography and endoscopic ultrasound: a European Society of Gastrointestinal Endoscopy (ESGE) quality improvement initiative. United Eur Gastroenterol J. 2018 Dec; 6(10):1448-60.

17 Liu L, Li C, Huang Y, Jin H. Nonsteroidal anti-inflammatory drugs for endoscopic retrograde cholangiopancreatography postoperative pancreatitis prevention: a systematic review and meta-analysis. J Gastrointest Surg. 2019 Oct;23(10):1991-2001.

18 Lyu Y, Cheng Y, Wang B, Xu Y, Du W. What is impact of nonsteroidal anti-inflammatory drugs in the prevention of post-endoscopic retrograde cholangiopancreatography pancreatitis: a meta-analysis of randomized controlled trials. BMC Gastroenterol. 2018 Jul 4, 18(1): 106.

19 Horiguchi S, Kamisawa T. Major duodenal papilla and its normal anatomy. Dig Surg. 2010;27(2):90-3 
20 Millbourn E. On the excretory ducts of the pancreas in man, with special reference to their relations to each other, to the common bile duct and to the duodenum. Acta Anat. 1950;9(1-2):1-34.

21 Shahidi N, Ou G, Telford J, Enns R. When trainees reach competency in performing ERCP: a systematic review. Gastrointest Endosc. 2015;81(6):1337-42.

22 Voiosu T, Bengus A, Voiosu A, Rimbas M, Zlate A, Haidar A, et al. Trainee caseload correlates with ERCP success rates but not with procedure-related complications: results from a prospective study (the QUASIE cohort). Endosc Int Open. 2016 Apr;4(4):E40914.

23 Voiosu T, Bălănescu P, Voiosu A, Benguş A, Preda C, Umans DS, et al. Measuring trainee competence in performing endoscopic retrograde cholangiopancreatography: a systematic review of the literature. United Eur Gastroenterol J. 2019 Mar;7(2):239-49.

24 Voiosu T, Boskoski I, Voiosu AM, Benguș A, Ladic A, Klarin I, et al. Impact of trainee involvement on the outcome of ERCP procedures: results of a prospective multicenter observational trial. Endoscopy. 2020 Feb;52(2): $115-22$.

25 Hawes RH, Devière J. How i cannulate the bile duct. Endoscopy. 2018 Jan;50(1):75-7.

26 Cortas GA, Mehta SN, Abraham NS, Barkun AN. Selective cannulation of the common bile duct: a prospective randomized trial comparing standard catheters with sphincterotomes. Gastrointest Endosc. 1999 Dec;50(6):775-9.

27 Tse F, Yuan Y, Moayyedi P, Leontiadis GI. Guidewire-assisted cannulation of the common bile duct for the prevention of post-endoscopic retrograde cholangiopancreatography (ERCP) pancreatitis. Cochrane Database Syst Rev. 2012;12(12):CD009662.

28 Kitamura K, Yamamiya A, Ishii Y, Sato Y, Iwata T, Nomoto T, et al. 0.025-inch vs. 0.035inch guide wires for wire-guided cannulation during endoscopic retrograde cholangiopancreatography: a randomized study. World J Gastroenterol. 2015 Aug 14;21(30):9182-8.

29 Bourke MJ, Costamagna G, Freeman ML. Biliary cannulation during endoscopic retrograde cholangiopancreatography: core technique and recent innovations. Endoscopy. 2009 Jul;41(7):612-7.

30 Park JS, Jeong S, Lee DH. Effectiveness of a novel highly flexible-tip guidewire on selective biliary cannulation compared to conventional guidewire: randomized controlled study. Dig Endosc. 2018;30(2):245-51.

31 Bassi M, Luigiano C, Ghersi S, Fabbri C, Gibiino G, Balzani L, et al. A multicenter randomized trial comparing the use of touch versus no-touch guidewire technique for deep biliary cannulation: the TNT study. Gastrointest Endosc. 2018 Jan;87(1):196-201.

32 Pécsi D, Farkas N, Hegyi P, Balaskó M, Czimmer J, Garami A, et al. Transpancreatic sphincterotomy has a higher cannulation success rate than needle-knife precut papilloto- my: a meta-analysis. Endoscopy. 2017 Sep; 49(9):874-87.

33 Mammen A, Haber G. Difficult biliary access: advanced cannulation and sphincterotomy technique. Gastrointest Endosc Clin N Am. 2015 Oct;25(4):619-30.

34 Wicks AC, Robertson GS, Veitch PS. Structured training and assessment in ERCP has become essential for the Calman era. Gut. 1999 Jul;45(1):154-6.

35 Choudhary A, Winn J, Siddique S, Arif M, Arif Z, Hammoud GM, et al. Effect of precut sphincterotomy on post-endoscopic retrograde cholangiopancreatography pancreatitis: a systematic review and meta-analysis. World J Gastroenterol. 2014 Apr 14;20(14): 4093-101.

36 Wen J, Li T, Lu Y, Bie L-K, Gong B. Comparison of efficacy and safety of transpancreatic septotomy, needle-knife fistulotomy or both based on biliary cannulation unintentional pancreatic access and papillary morphology. Hepatobiliary Pancreat Dis Int. 2019 Feb; 18(1):73-8.

37 Jang SI, Kim DU, Cho JH, Jeong S, Park JS, Lee DH, et al. Primary needle-knife fistulotomy versus conventional cannulation method in a high-risk cohort of post-endoscopic retrograde cholangiopancreatography pancreatitis. Am J Gastroenterol. 2020 Apr;115(4): 616-24.

38 Horiuchi A, Nakayama Y, Kajiyama M, Tanaka N. Effect of precut sphincterotomy on biliary cannulation based on the characteristics of the major duodenal papilla. Clin Gastroenterol Hepatol. 2007 Sep;5(9):1113-8.

39 Goldberg E, Titus M, Haluszka O, Darwin P. Pancreatic-duct stent placement facilitates difficult common bile duct cannulation. Gastrointest Endosc. 2005 Oct;62(4):592-6.

40 Cennamo V, Fuccio L, Zagari RM, Eusebi LH, Ceroni L, Laterza L, et al. Can early precut implementation reduce endoscopic retrograde cholangiopancreatography-related complication risk? Meta-analysis of randomized controlled trials. Endoscopy. 2010 May;42(5): 381-8.

41 Sundaralingam P, Masson P, Bourke MJ. Early precut sphincterotomy does not increase risk during endoscopic retrograde cholangiopancreatography in patients with difficult biliary access: a meta-analysis of randomized controlled trials. Clin Gastroenterol Hepatol. 2015;13(10):1722-e2.

42 Tang Z, Yang Y, Yang Z, Meng W, Li X. Early precut sphincterotomy does not increase the risk of adverse events for patients with difficult biliary access: a systematic review of randomized clinical trials with meta-analysis and trial sequential analysis. Medicine. 2018 Sep; 97(36):e12213

43 Chen J, Wan JH, Wu DY, Shu WQ, Xia L, Lu $\mathrm{NH}$. Assessing quality of precut sphincterotomy in patients with difficult biliary access: an updated meta-analysis of randomized controlled trials. J Clin Gastroenterol. 2018 Aug; 52(7):573-8.
44 Herreros de Tejada A, Calleja JL, Díaz G, Pertejo V, Espinel J, Cacho G, et al. Doubleguidewire technique for difficult bile duct cannulation: a multicenter randomized, controlled trial. Gastrointest Endosc. 2009 Oct; 70(4):700-9.

45 Sasahira N, Kawakami H, Isayama H, Uchino R, Nakai Y, Ito Y, et al. Early use of doubleguidewire technique to facilitate selective bile duct cannulation: the multicenter randomized controlled EDUCATION trial. Endoscopy. 2015 May;47(5):421-9.

46 Tse F, Yuan Y, Moayyedi P, Leontiadis GI, Barkun AN. Double-guidewire technique in difficult biliary cannulation for the prevention of post-ERCP pancreatitis: a systematic review and meta-analysis. Endoscopy. 2017 Jan;49(1):15-26.

47 Ito K, Fujita N, Noda Y, Kobayashi G, Obana $\mathrm{T}$, Horaguchi J, et al. Can pancreatic duct stenting prevent post-ERCP pancreatitis in patients who undergo pancreatic duct guidewire placement for achieving selective biliary cannulation? A prospective randomized controlled trial. J Gastroenterol. 2010 Nov;45(11): 1183-91.

48 Ito K, Horaguchi J, Fujita N, Noda Y, Kobayashi G, Koshita S, et al. Clinical usefulness of double-guidewire technique for difficult biliary cannulation in endoscopic retrograde cholangiopancreatography. Dig Endosc. 2014 May;26(3):442-9.

49 Wang X, Ren G, Xi Y, Luo H, Liang S, Wang $\mathrm{B}$, et al. Learning curve of double-guidewire technique by trainees during hands-on endoscopic retrograde cholangiopancreatography training. J Gastroenterol Hepatol. 2020 Dec; 35(12):2176-83.

50 Sugiyama H, Tsuyuguchi T, Sakai Y, Mikata $\mathrm{R}$, Yasui S, Watanabe Y, et al. Transpancreatic precut papillotomy versus double-guidewire technique in difficult biliary cannulation: prospective randomized study. Endoscopy. 2018 Jan;50(1):33-9.

51 Goff JS. Common bile duct pre-cut sphincterotomy: transpancreatic sphincter approach. Gastrointest Endosc. 1995 May;41(5):502-5.

52 Kahaleh M, Tokar J, Mullick T, Bickston SJ, Yeaton P. Prospective evaluation of pancreatic sphincterotomy as a precut technique for biliary cannulation. Clin Gastroenterol Hepatol. 2004 Nov;2(11):971-7.

53 Sakai Y, Tsuyuguchi T, Sugiyama H, Kurosawa J, Saito M, Tawada K, et al. Transpancreatic precut papillotomy in patients with difficulty in selective biliary cannulation. Hepatogastroenterology. 2011 Nov-Dec;58(112): $1853-8$

54 Kozarek R. Flail, flay, or fail: needle-knife versus transpancreatic sphincterotomy to access the difficult-to-cannulate bile duct during ERCP. Endoscopy. 2017 Sep;49(9):842-3.

55 Pécsi D, Farkas N, Hegyi P, Varjú P, Szakács Z, Fábián A, et al. Transpancreatic sphincterotomy is effective and safe in expert hands on the short term. Dig Dis Sci. 2019 Sep;64(9): 2429-44. 
56 Koskensalo V, Udd M, Rainio M, Halttunen J, Sipilä M, Lindström O, et al. Transpancreatic biliary sphincterotomy for biliary access is safe also on a long-term scale. Surg Endosc. 2021;35(1):104-12.

57 Barakat MT, Girotra M, Huang RJ, Choudhary A, Thosani NC, Kothari S, et al. Goff septotomy is a safe and effective salvage biliary access technique following failed cannulation at ERCP. Dig Dis Sci. 2021;66(3):866-72.

58 Hamada T, Yasunaga H, Nakai $Y$, Isayama $H$, Horiguchi H, Fushimi K, et al. Severe bleeding after percutaneous transhepatic drainage of the biliary system: effect of antithrombotic agents: analysis of 34,606 cases from a Japanese nationwide administrative database. Radiology. 2015 Feb;274(2):605-13.

59 Nennstiel S, Weber A, Frick G, Haller B, Meining A, Schmid RM, et al. Drainage-related complications in percutaneous transhepatic biliary drainage: an analysis over 10 years. J Clin Gastroenterol. 2015 Oct;49(9):764-70.

60 Wiersema MJ, Sandusky D, Carr R, Wiersema LM, Erdel WC, Frederick PK. Endosonography-guided cholangiopancreatography. Gastrointest Endosc. 1996 Feb;43(2 Pt 1):102-6.
61 Giovannini M, Moutardier V, Pesenti C, Bories E, Lelong B, Delpero JR. Endoscopic ultrasound-guided bilioduodenal anastomosis: a new technique for biliary drainage. Endoscopy. 2001 Oct;33(10):898-900.

62 Salerno R, Davies SEC, Mezzina N, Ardizzone S. Comprehensive review on EUS-guided biliary drainage. World J Gastrointest Endosc. 2019 May 16;11(5):354-64.

63 Khan MA, Akbar A, Baron TH, Khan S, Kocak M, Alastal Y, et al. Endoscopic ultrasound-guided biliary drainage: a systematic review and meta-analysis. Dig Dis Sci. 2016 Mar;61(3):684-703.

64 Wang K, Zhu J, Xing L, Wang Y, Jin Z, Li Z. Assessment of efficacy and safety of EUSguided biliary drainage: a systematic review. Gastrointest Endosc. 2016 Jun;83(6):121827.

65 Guo J, Giovannini M, Sahai AV, Saftoiu A, Dietrich CF, Santo E, et al. A multi-institution consensus on how to perform EUS-guided biliary drainage for malignant biliary obstruction. Endosc Ultrasound. 2018 Nov-Dec; $7(6): 356-65$

66 Sharaiha RZ, Khan MA, Kamal F, Tyberg A, Tombazzi CR, Ali B, et al. Efficacy and safety of EUS-guided biliary drainage in comparison with percutaneous biliary drainage when ERCP fails: a systematic review and metaanalysis. Gastrointest Endosc. 2017 May; 85(5):904-14.

67 Dhir V, Itoi T, Khashab MA, Park DH, Teoh AYB, Attam R, et al. Multicenter comparative evaluation of endoscopic placement of expandable metal stents for malignant distal common bile duct obstruction by ERCP or EUS-guided approach. Gastrointest Endosc. 2015 Apr;81(4):913-23.

68 Kylänpää L, Koskensalo V, Saarela A, Ejstrud P, Udd $M$, Lindström $O$, et al. Transpancreatic biliary sphincterotomy versus double guidewire in difficult biliary cannulation: a randomized controlled trial. Endoscopy. 2021.

69 Adler DG, Lieb JG 2nd, Cohen J, Pike IM, Park WG, Rizk MK, et al. Quality indicators for ERCP. Am J Gastroenterol. 2015 Jan; 110(1):91-101.

70 Kahaleh M, Artifon EL, Perez-Miranda M, Gupta K, Itoi T, Binmoeller KF, et al. Endoscopic ultrasonography guided biliary drainage: summary of consortium meeting, May 7th, 2011, Chicago. World J Gastroenterol. 2013 Mar 7;19(9):1372-9. 